\title{
Primary Care Approach to Proteinuria
}

\author{
Amir Said Alizadeh Naderi, MD, and Robert F. Reilly, MD
}

Proteinuria is a common finding in primary care practice. Most adolescents who are diagnosed with proteinuria through screening urinalysis do not have renal disease, and the proteinuria will usually resolve on repeat testing. In contrast, proteinuria is suggestive of kidney disease in patients with diabetes mellitus, hypertension, primary renal disease, or other systemic illnesses. Quantification of proteinuria can be used longitudinally to monitor therapeutic effects of treatment of the underlying disease. Given the multitude of clinical settings in which proteinuria can occur, we suggest an algorithm that may help clinicians differentiate between benign and serious etiologies of proteinuria. ( $\mathrm{J}$ Am Board Fam Med 2008;21:569-74.)

During a time when uroscopy was the only diagnostic tool for diagnosing renal diseases, Hippocrates described the association between "bubbles on the surface of the urine" and kidney disease. ${ }^{1}$ In the seventeenth century Frederick Dekkers described how urine samples became caseous after exposure to heat and acetic acid, but it took another 200 years until Richard Bright associated proteinuria with kidney disease. ${ }^{2,3}$ Nowadays, the presence of proteinuria is routinely and easily assessed in clinical practice. This article provides an overview of the most common causes of proteinuria in adults, describes ways to assess proteinuria, and offers an algorithmic approach to differentiate benign from serious etiologies of proteinuria.

\section{Proteinuria}

Proteinuria is a common clinical finding in primary care practice. ${ }^{4}$ Healthy kidneys excrete less than 150 $\mathrm{mg}$ of protein/day, of which approximately $20 \mathrm{mg}$ is albumin. Tamm-Horsfall mucoproteins, which is secreted by tubular cells and immunoglobulins, are responsible for the remaining part of physiologic proteinuria. Microalbuminuria is defined as daily

This article was externally peer reviewed.

Submitted 22 March 2007; revised 14 April 2008; accepted 17 April 2008.

From the Department of Internal Medicine, The University of Texas Southwestern Medical Center at Dallas (ASAN, RFR); the Division of Nephrology, VA North Texas Health Care System, Dallas (RFR).

Funding: none.

Conflict of interest: none declared.

Corresponding author: Amir Said Alizadeh Naderi, MD, Department of Internal Medicine, The University of Texas Southwestern Medical Center at Dallas, 5323 Harry Hines Boulevard, Dallas, TX 75390-8837 (E-mail: Robert.Reilly2@ va.gov). excretion of 30 to $300 \mathrm{mg}$ of albumin/day and is an early and sensitive marker of diabetic nephropathy. ${ }^{5-7}$

Microalbuminuria is associated with an increased risk of cardiovascular disease in patients with and without diabetes and/or hypertension. ${ }^{8-10}$ Proteinuria has been shown to be an independent risk factor for the progression of kidney disease rather than simply being a marker for glomerular dysfunction. ${ }^{11}$ The daily excretion of more than $3.5 \mathrm{~g}$ of protein is called nephrotic range proteinuria. The discussion of pathophysiologic mechanisms of proteinuria is beyond the scope of this article (for more information, read a recent review article ${ }^{12}$ ). Table 1 summarizes the different types of proteinuria.

\section{Classification of Proteinuria}

Proteinuria can be classified into 3 broad categories: (1) overflow proteinuria, (2) tubular proteinuria, and (3) glomerular proteinuria.

\section{Overflow proteinuria}

Low-molecular weight proteins filtered by the glomerulus are almost entirely reabsorbed in the proximal tubule. During states of increased low-molecular weight protein production and subsequent filtration, the amount of filtered protein exceeds tubular reabsorptive capacity, leading to proteinuria. In multiple myeloma, excessive amounts of immunoglobulin light chains are produced, which can be detected in the urine because of the limited reabsorptive capacity of the proximal tubule.

\section{Tubular proteinuria}

Tubulointerstitial diseases (eg, Fanconi syndrome) can lead to decreased reabsorptive capacity of the proximal tubule and up to $2 \mathrm{~g}$ of proteinuria per day 


\begin{tabular}{lcr}
\hline & Albuminuria & Proteinuria \\
\hline Physiologic range proteinuria & $<20 \mathrm{mg} / \mathrm{day}(15 \mu \mathrm{g} / \mathrm{min})$ & $<150 \mathrm{mg} / \mathrm{day}$ \\
Microalbuminuria & $30-300 \mathrm{mg} / \mathrm{day}(20-200 \mu \mathrm{g} / \mathrm{min})$ & \\
Macroalbuminuria & $>300 \mathrm{mg} / \mathrm{day}(>200 \mu \mathrm{g} / \mathrm{min})$ & $>3.5 \mathrm{~g} / \mathrm{day}$ \\
Nephrotic range proteinuria & & \\
\hline
\end{tabular}

because of impaired tubular absorption of filtered albumin, as well as loss of tubular proteins $\left(\beta_{2}\right.$ microglobulin).

\section{Glomerular proteinuria}

Glomerular proteinuria is a sensitive marker for glomerular disease. It develops as a result of increased filtration of macromolecules (eg, albumin) across the glomerular capillary wall (Table 2).

\section{Quantification of Proteinuria}

Proteinuria can be quantified by different means. Urine dipstick testing, spot urine specimen analysis, timed urine collection, and the sulfosalicylic acid test are the most commonly employed tests.

\section{Dipstick testing}

Urinary dipstick testing is routinely performed in clinical practice. It is an inexpensive test that is used for screening of different disorders, including urinary, gastrointestinal, metabolic, and hematologic diseases. Besides quantification of proteinuria, urinary dipstick testing provides valuable information about other parameters, including urinary blood, glucose, ketones, $\mathrm{pH}$, specific gravity, leukocyte esterase, and nitrite. The standard dipstick measures albumin concentration in the urine via a colorimetric reaction between albumin and tetrabromophenol blue, causing different color shading depending on the albumin concentration in the sample. If the urine is dilute (low specific gravity), urine albumin concentration is decreased and is occasionally not detected by dipstick testing. The most conservative approach would be to repeat the value and, if positive, to obtain a protein/ creatinine or albumin-to-creatinine ratio. Importantly, as dipsticks only measure albuminuria, other proteins like renally excreted immunoglobulin light chains in multiple myeloma are not detected. A positive urinary dipstick is a useful screening test for proteinuria. Its limitations are quantification of proteinuria and its inadequacy to detect immunoglobulin light chains.

\section{Spot urine analysis}

Spot urine analysis for protein-to-creatinine ratio (UPCR) and albumin-to-creatinine ratio (UACR) are currently preferred to the 24-hour urine collection for quantification of daily proteinuria given the greater convenience of spot urine sampling. Measurement of UACR was shown to be as good as a 24-hour urine collection for the quantification of proteinuria (strength of evidence A). ${ }^{16-18}$ The UACR is used to assess for microalbuminuria, whereas the UPCR can be used when proteinuria of more than $300 \mathrm{mg}$ /day is suspected. First morning specimens are preferable.

The National Kidney Foundation recommends annual screening for proteinuria in diabetics using the UACR in a spot urine sample. Because the amount of spot urine proteinuria might fluctuate, a positive UACR should be confirmed (in the absence of a urinary tract infection) with 2 additional first-void specimens collected over the next 3 to 6 months (strength of evidence B). ${ }^{19} \mathrm{It}$ is worth mentioning that the UACR is a more sensitive screening test than the UPCR. UPCR is less expensive for a patient with established proteinuria and can be used longitudinally to evaluate therapeutic efforts to reduce proteinuria.

Clinicians should be aware that the accuracy of estimating proteinuria from a random urine specimen is diminished if creatinine excretion is substantially different from $1 \mathrm{~g} /$ day. Thus, the albumin-to-creatinine ratio will underestimate protein excretion in a muscular man with a high rate of creatinine excretion and will overestimate urinary protein excretion in a cachectic patient with low muscle mass and low creatinine excretion.

\section{4-hour urine collection}

Twenty-four-hour urine collection is the most accurate test for quantification of proteinuria and is also used for qualitative urinalysis. ${ }^{20,21}$ However, the test becomes inaccurate when difficulties with urine collection are encountered. To minimize collection and handling errors, patients should receive detailed instructions about 24-hour urine collection. 


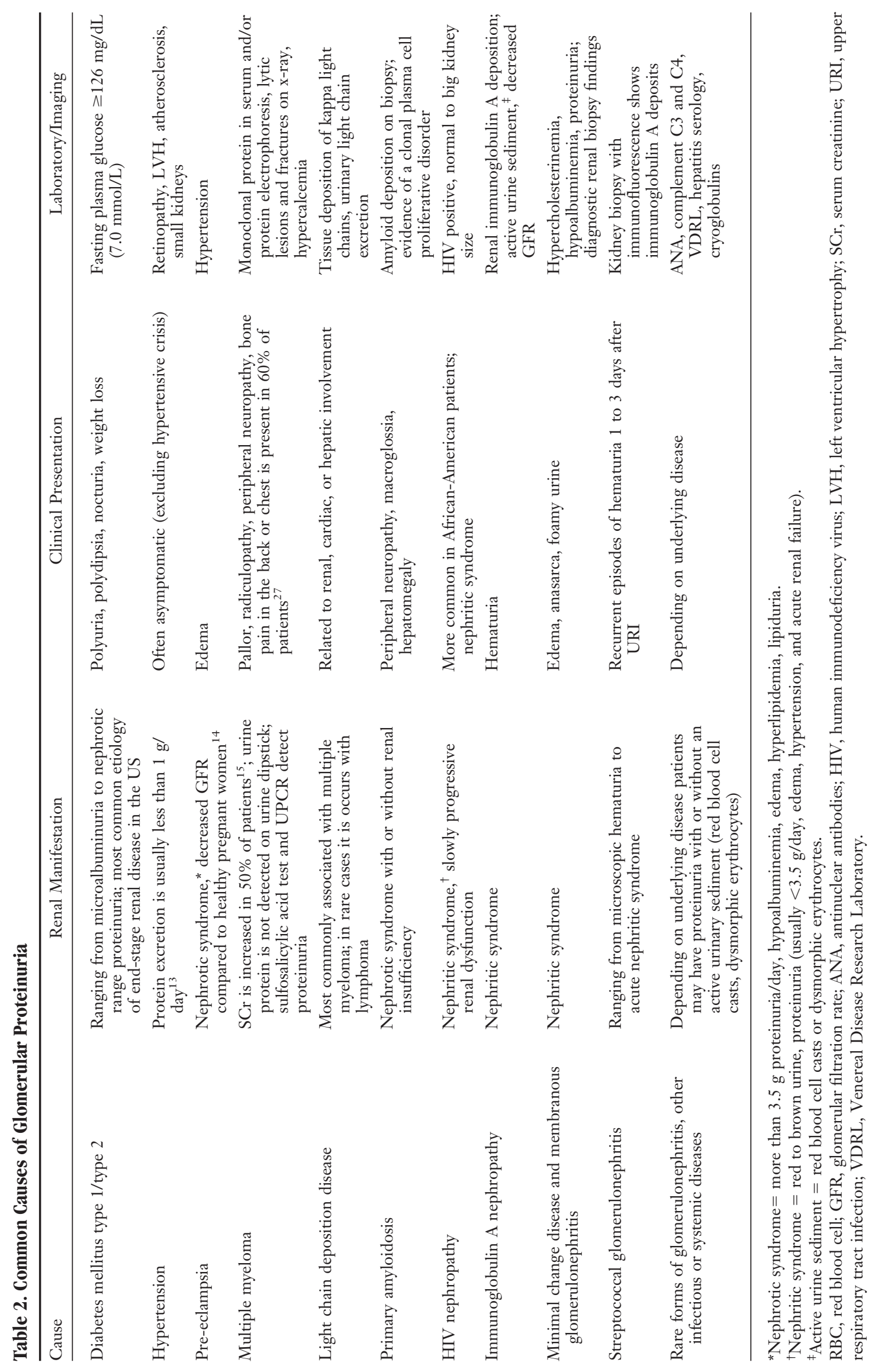




\section{Box 1. Patient Instructions for 24-hr Urine Collection}

On the first day of collection, urinate into the toilet when you get up in the morning. Afterward, collect all urine in a special container for the next 24 hours. On the second day, urinate into the container when you get up in the morning.

- Cap the container.

- Keep the sample in the refrigerator during the collection period.

- Label the container with your name, the date, and the time of completion and return it to your healthcare provider.

A timed urine collection is often not collected properly. To determine the completeness of a 24hour urine collection, the total daily urine creatinine is often used as a standard. In patients younger than 50 years, normal daily urinary creatinine range is 15 to $20 \mathrm{mg} / \mathrm{kg}$ lean body weight for women and 20 to $25 \mathrm{mg} / \mathrm{kg}$ lean body weight for men. In older people, the production of daily creatinine is reduced, primarily because of decreased muscle mass. In the latter case, calculating the ratio of creatinine clearance measured by 24-hour collection to the estimated creatinine clearance from a serum sample can help ensure proper collection. A ratio of 0.9:1.1 suggests a complete 24-hour urine collection because both estimated and measured creatinine clearances are roughly equal. ${ }^{22}$ Although in many cases the timed urine collection is incomplete, measurement of UACR and UPCR from this urine collection is still helpful and may be more accurate than a spot urine specimen.

\section{Sulfosalicylic Acid Test}

The sulfosalicylic acid test detects all types of urinary proteins. This characteristic makes the sulfosalicylic acid test useful in the diagnosis of multiple myeloma, which is characterized by urinary excretion of immunoglobulin light chains (these are not detected by urine dipstick testing). A sulfosalicylic acid test should not be used as a screening test because it cannot detect small quantities of monoclonal free light chains. In the latter case, examination of 24-hour urine samples using electrophoresis and immunofixation is more sensitive. $^{23}$ Overall, the sulfosalicylic acid test is no longer routinely used in the assessment of proteinuria.

\section{Box 2. 24-hr Urine Collection in the Diagnosis of Orthostatic Proteinuria}

The test requires a 24-hour urine collection in 2 different jugs, which can be labeled as "day time urine" and "night time urine." During the collection time the urine needs to be stored in a refrigerator. The first morning urine is discarded. For the rest of the day all urine is collected in the daytime urine jug. In the evening, the patient should lie down for approximately 2 hours before going to sleep. Just before sleeping, the patient should void for the last time during the day and add this urine to the daytime urine jug. By lying down before the nighttime collection contamination of the nighttime urine with urine formed during the day when the patient was upright is avoided. The following morning ( 8 hours after the last night time collection) the patient shall collect the first morning urine in the nighttime urine jug. Both urine jugs are taken to the laboratory thereafter.

\section{Transient and Orthostatic Proteinuria}

The first step in the assessment of proteinuria is to differentiate between benign and serious causes of proteinuria. In adolescents, proteinuria can be induced by strenuous exercise, fever, and extreme cold. $^{24,25}$ In all of these circumstances, proteinuria resolves spontaneously after the cessation of the causal factor, so an extensive work-up is not needed. ${ }^{26}$

$\mathrm{Up}$ to $5 \%$ of adolescents may have orthostatic or postural proteinuria. This benign condition is characterized by an increase in protein excretion in the upright position, which normalizes when the patient is recumbent. As a rule of thumb, patients with orthostatic proteinuria excrete less than $1 \mathrm{~g}$ of protein over 24 hours in the upright position; the rate of protein excretion completely normalizes in a supine position ( $<50 \mathrm{mg}$ per 8 hours). The long-term prognosis for adolescents with orthostatic proteinuria is excellent, even after decades of follow-up. ${ }^{27}$ Orthostatic proteinuria is uncommon over the age of 30 . Young adults with proteinuria should be evaluated by a nephrologist if proteinuria persists on repeat testing, especially if they develop an increase in serum creatinine concentration or when there are associated abnormalities in the urinary sediment. 


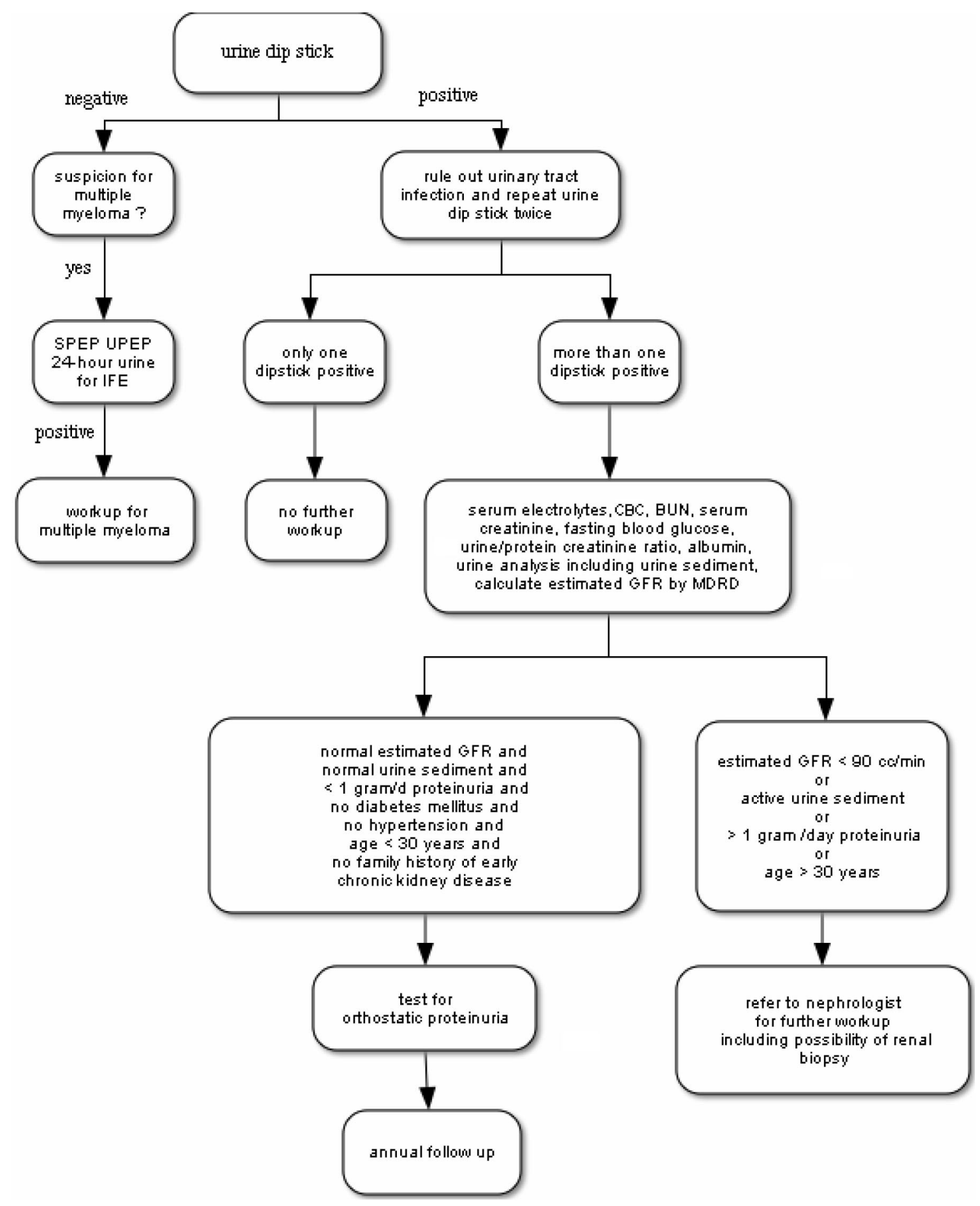

Figure 1. Algorithmic approach to proteinuria. SPEP, serum protein electrophoresis; UPEP, urine protein electrophoresis; IFE, Immunofixation electrophoresis; GFR, glomerular filtration rate; MDRD, Modification of Diet in Renal Disease equation.

The gold standard for assessment of orthostatic proteinuria is the collection of a 24-hour urine sample.
Alternatively, a normal UPCR of $<0.15$ $\mathrm{mg} / \mathrm{mg}$ on a first morning spot urine specimen and an elevated total protein to creatinine ratioof 
more than $0.15 \mathrm{mg} / \mathrm{mg}$ on a second upright spot urine specimen is indicative of orthostatic proteinuria.

\section{Conclusion}

Proteinuria is a common diagnosis in primary care practice. Using an algorithm as suggested in this paper (Figure 1) can help the clinician to distinguish between benign and serious causes of proteinuria. Physicians need to be aware that although patients with diabetes and/or hypertension commonly develop proteinuria in the setting of their underlying disease, proteinuria might also develop as a consequence of a second disease. Thus, all adults should also have a urine sediment examination and urine protein electrophoresis to exclude Bence Jones proteinuria. The presence of unexplained proteinuria or active urine sediment suggestive of a nephritic syndrome requires nephrology consultation.

\section{References}

1. Adams F. The genuine works of Hippocrates, vol 2. London: C \& J Adlars Printers; 1849.

2. Bright R. Cases and observations, illustrative of renal disease accompanied with the secretion of albuminous urine. London Medical Gazette 1835;72-74.

3. Cameron JS. Milk or albumin? The history of proteinuria before Richard Bright. Nephrol Dial Transplant 2003;18:1281-5.

4. Carroll MF, Temte JL. Proteinuria in adults: a diagnostic approach. Am Fam Physician 2000;62:1333-40.

5. Remuzzi G, Schieppati A, Ruggenenti P. Clinical practice. Nephropathy in patients with type 2 diabetes. N Engl J Med 2002;346:1145-51.

6. Viberti GC, Hill RD, Jarrett RJ, Argyropoulos A, Mahmud U, Keen H. Microalbuminuria as a predictor of clinical nephropathy in insulin-dependent diabetes mellitus. Lancet 1982;1:1430-2.

7. Parvanova AI, Trevisan R, Iliev IP, et al. Insulin resistance and microalbuminuria: a cross-sectional, case-control study of 158 patients with type 2 diabetes and different degrees of urinary albumin excretion. Diabetes 2006;55:1456-62.

8. Gerstein HC, Mann JF, Yi Q, et al. Albuminuria and risk of cardiovascular events, death, and heart failure in diabetic and nondiabetic individuals. JAMA 2001;286:421-6.

9. Wachtell K, Ibsen H, Olsen MH, et al. Albuminuria and cardiovascular risk in hypertensive patients with left ventricular hypertrophy: the LIFE study. Ann Intern Med 2003;139:901-6.

10. Hillege HL, Fidler V, Diercks GF, et al. Urinary albumin excretion predicts cardiovascular and noncardiovascular mortality in general population. Circulation 2002;106:1777-82.
11. Burton C, Harris KP. The role of proteinuria in the progression of chronic renal failure. Am J Kidney Dis 1996;27:765-75.

12. Tryggvason K, Patrakka J and Wartiovaara J. Hereditary proteinuria syndromes and mechanisms of proteinuria. N Engl J Med 2006;354:1387-401.

13. Harvey JM, Howie AJ, Lee SJ, et al. Renal biopsy findings in hypertensive patients with proteinuria. Lancet 1992;340:1435-6.

14. Waugh JJ, Clark TJ, Divakaran TG, Khan KS, Kilby MD. Accuracy of urinalysis dipstick techniques in predicting significant proteinuria in pregnancy. Obstet Gynecol 2004;103:769-77.

15. Kyle RA, Gertz MA, Witzig TE, et al. Review of 1027 patients with newly diagnosed multiple myeloma. Mayo Clin Proc 2003;78:21-33.

16. Ginsberg JM, Chang BS, Matarese RA, Garella S. Use of single voided urine samples to estimate quantitative proteinuria. N Engl J Med 1983;309:1543-6.

17. Schwab SJ, Christensen RL, Dougherty K, Klahr S. Quantitation of proteinuria by the use of protein-tocreatinine ratios in single urine samples. Arch Intern Med 1987;147:943-4.

18. Chitalia VC, Kothari J, Wells EJ, et al. Cost-benefit analysis and prediction of 24-hour proteinuria from the spot urine protein-creatinine ratio. Clin Nephrol 2001;55:436-47.

19. KDOQI Clinical Practice Guidelines and Clinical Practice Recommendations for Diabetes and Chronic Kidney Disease. Am J Kidney Dis 2007; 49:S12-154.

20. Bazzi C, Petrini C, Rizza V, Arrigo G, Beltrame A, D'Amico G. Characterization of proteinuria in primary glomerulonephritides. SDS-PAGE patterns: clinical significance and prognostic value of low molecular weight ("tubular") proteins. Am J Kidney Dis 1997;29:27-35.

21. Reichert LJ, Koene RA, Wetzels JF. Urinary excretion of beta 2 -microglobulin predicts renal outcome in patients with idiopathic membranous nephropathy. J Am Soc Nephrol 1995;6:1666-9.

22. Wilmer WA, Rovin BH, Hebert CJ, Rao SV, Kumor K, Hebert LA. Management of glomerular proteinuria: a commentary. J Am Soc Nephrol 2003;14:3217-32.

23. Keren DF. Procedures for the evaluation of monoclonal immunoglobulins. Arch Pathol Lab Med 1999; 123:126-32.

24. Poortmans JR. Postexercise proteinuria in humans. Facts and mechanisms. JAMA 1985;253:236-40.

25. Houser MT, Jahn MF, Kobayashi A, Walburn J. Assessment of urinary protein excretion in the adolescent: effect of body position and exercise. J Pediatr 1986;109:556-61.

26. Robinson RR. Isolated proteinuria in asymptomatic patients. Kidney Int 1980;18:395-406.

27. Rytand DA, Spreiter S. Prognosis in postural (orthostatic) proteinuria: forty to fifty-year follow-up of 6 patients after diagnosis by Thomas Addis. N Engl J Med 1981;305:618-21. 